УДК 115

DOI: 10.18413/2408-932X-2019-5-4-0-3

Савинцев В. И. ПСИХОЛОГИЧЕСКОЕ ВРЕМЯ В ТВОРЧЕСТВЕ Н. Я. ГРОТА И В. ВУНДТА ${ }^{1}$

Балтийский федеральный университет имени Иммануила Канта, ул. А. Невского, д. 14, г. Калининград 236016, Россия; vyacheslav-savincev@yandex.ru

\begin{abstract}
Аннотация. В центре внимания исследования, представленного в статье, - историко-философская проблема интерпретации Н.Я. Гротом психологического времени. Будучи одним из основателей Московской психологической школы, Грот полагал необходимым сочетание естественнонаучных и метафизических методов в исследовании душевной деятельности. Его взгляд отличался от популярного в то время экспериментального подхода В. Вундта. Грот был против того, что Вундт стандартизировал чувственные реакции, сведя их исключительно к пространственно-временным характеристикам. На основании методов философской реконструкции, компаративистского и герменевтического предпринята попытка сопоставления подходов Вундта и Грота. Кроме того, осмыслена продуктивность представления о психологическом времени в рамках концепции энергетизма Н.Я. Грота. Установлено, что оба философа воспринимают время как априорную форму чувственности. Согласно их исследованиям, чувство времени у человечества было развито в процессе обыденного опыта. При этом оба философа разделяют его на субъективное и объективное. Последнее не атрибут материи, но природный коррелят душевных реакций. Различие в подходах выразилось в том, что в трактовке Грота душевные процессы (мышление, память, воображение и пр.) не подчинены пространственно-временным описаниям, а потому, помимо наблюдения и эксперимента, в психологии должны быть задействованы методы метафизики.
\end{abstract}

Ключевые слова: время; пространство; метафизика; душа; экспериментальная психология; энергия; восприятие; мышление

Для цитирования: Савинцев В.И. Психологическое время в творчестве Н.Я. Грота и В. Вундта // Научный результат. Социальные и гуманитарные исследования. 2019. Т. 5. № 4. C.32-38. DOI: 10.18413/2408-932X-2019-5-4-0-3

\title{
V. I. Savintsev
}

PSYCHOLOGICAL TIME IN THE STUDIES OF N. J. GROTH AND W. WUNDT

Immanuel Kant Baltic Federal University, 14 A. Nevsky St., Kaliningrad 236016, Russia; vyacheslav-savincev@yandex.ru

\begin{abstract}
The object of the study is N. J. Groth's interpretation of the manifestation of psychological time in consciousness. N. J. Groth was a philosopher and psychologist who combined scientific and empirical methods, as well as metaphysical research in the study of mental activity. He did a discussion with the famous psycholo-
\end{abstract}

\footnotetext{
${ }^{1}$ Исследование выполнено при финансовой поддержке РФФИ: проект № 19-011-00302А.
} 
gist W. Wundt. N. J. Groth postulate that the higher forms of consciousness (thinking, memory, intuition) are not interpreted in the space-time discourse. These are forms of being not subject to the laws of nature. The methods used in the study are comparative, hermeneutic and philosophical reconstruction. The study presents the results: 1) N. J. Groth and W. Wundt believe that time is a priori a form of feeling; 2) both philosophers introduce the concepts of objective and subjective time. However, time functions only within the boundaries of the human body; 3 ) the function of the sensation of time is not innate, but arise in experience; 4) N. J. Groth argues that to the deep forms of consciousness, temporal, spatial, quantitative parameters are not applicable. It is an ideal form of being which only metaphysics can comprehend.

Key words: time; space; metaphysics; soul; experimental psychology; energy; perception; thinking

For citation: Savintsev, V. I. (2019), "Psychological time in the studies of N. J. Groth and W. Wundt", Research Result. Social Studies and Humanities, 5 (4), 32-38, DOI: 10.18413/2408-932X-2019-5-4-0-3

Разработанная Н.Я. Гротом концепция психологического времени является важным элементом учения, получившего название «монодуализм». Впервые этот термин был представлен Н.Я. Гротом в работе «Джордано Бруно и пантеизм», определившей переход русского мыслителя от увлечения первым позитивизмом к метафизике. Монодуализм есть «органический синтез» монизма и дуализма, крайних философских позиций, объединенных в «чемто высшем» (Грот, 1885: 23). И таким «высшим», на наш взгляд, у Грота становится человеческая душа. Не случайно друг и вдохновитель Н.Я. Грота В.С. Соловьев среди значимых и взаимосвязанных тем философа назвал именно те, которые связаны с душевной деятельностью: «В последние десять-двенадцать лет на моих глазах, кроме множества второстепенных этюдов, он был занят тремя важнейшими вопросами: о свободе воли, о природе времени и о превращениях энергии» (Соловьев, 1911: 149).

Тема времени, конституирующая все остальные, представлена Н.Я. Гротом в трех статьях, напечатанных изначально в журнале «Вопросы философии и психологии». Философ полагал, что, раскрыв психологическую природу времени, исследователи научатся правильнее объяснять динамику чувственных реакций человека, не относя их ни к физиологическим проявлениям организма, ни к необъяснимым феноменам религиозного опыта. Тема, по мысли Н.Я. Грота, предельно актуальная, поскольку в международной научной среде наметились тенденции сведения психологии к «физиологии мозга и органов чувств», а метафизики - к теории познания, отделу соответствующей позитивистской психологии. Время в таких исследованиях рассматривается как врожденная априорная способность, лишь регистрирующая последовательность явлений души. И, казалось бы, в этом нет ничего вопиющего, если бы не растущая уверенность психологов-позитивистов, что иных способов объяснения проявлений душевной активности не существует. По мысли Н.Я. Грота, формирующийся «физиологический» подход в психологии может привести к тому, что такие сложные виды душевной деятельности, как мышление, интуиция, память также начнут сводить к заданным пространственно-временным стандартам. Среди интеллектуалов, способствующих развитию этой тенденции, Грот называет И. Канта и В. Вундта, чьи открытия явились поворотными для психологии XIX в. Кант, по мыли Грота, актуализировал в оценках познавательной деятельности психологическое значение чувств, которым предшествующие философы не придавали серьезного значения, а 
Вундт изобрел научные методы их глубинного и хронометрического исследования. Вместе с тем, психология, опирающаяся на кантовские традиции, усвоила не только новации, но и «ошибки» в интерпретации чувственных реакций, а также сопровождающих их априорных способностей восприятия пространства и времени. Грот поставил задачу переосмысления вышеуказанных априорных форм для дальнейшей коррекции представлений о душевной деятельности. Но перед тем как представить позицию Н.Я. Грота, обратимся к вопросу о времени у его интеллектуального соперника В. Вундта.

\section{1. Время в экспериментальной психологии В. Вундта}

Согласно Д.П. и С.Э. Шульцам, Россия была одной из стран, где идеи психолога-экспериментатора Вундта были хорошо известны благодаря созданным его учениками психологическим лабораториям (Шульц, Шульц, 2002: 77). Однако его концепция обсуждалась и в кругах исключительно философских, задолго до научнолабораторной популяризации. Так, например, В.С. Соловьев в 1895 г. в рецензии на книгу «Лекции о душе человека и животных» дает четкий структурирующий анализ экспериментального подхода Вундта к исследованию природы человеческих чувств. Он отмечает, с одной стороны, глубину идеи количественного и качественного подхода к измерению отдельных ощущений, а с другой, - выявляет несоответствие выводов Вундта фехнеровским расчетам соответствия интенсивности ощущения логарифму интенсивности раздражения (Соловьев, 1895). Рецензия В. Соловьева (как и работы других философов) показывает, насколько глубоким был интерес в русском обществе к зарубежным психологическим новациям, что, конечно, способствовало как обсуждению, так и выработке актуальных критических оценок его отдельных положений.

В. Вундт различал психологию метафизическую, занимающуюся сущностными вопросами души, и «эмпирическую», в основе которой лежат привнесенные из естественных наук познавательные методы и в которой сформулированы четкие исследовательские задачи. Эмпирическая или экспериментальная психология, по замыслу Вундта, должна в адекватных для науки понятиях и формах представить психическую сторону бытия, коррелирующую с физической. Именно потому основополагающим методом изучения психики для Вундта стал эксперимент. В трудах немецкого психолога можно выделить две стороны отношения ко времени. Вопервых, время - приобретенная способность различать явления в пространстве и, во-вторых, - один из эмпирических параметров скорости чувственных реакций. Забегая вперед, скажем, что Грот критиковал не столько дифференциацию вундтовских темпоральных форм, сколько их смешение в излагаемых выводах.

Относительно первого, психологического, аспекта Вундт говорит об объективном времени - мускульно-психических реакциях и субъективном времени - отношении к этим реакциям субъекта действия. Как видим, субъективное и объективное время реализуются в границах человеческой телесности. Имея разные источники, эти времена, по мысли Вундта, должны совпадать. Однако, как показывает опыт, в некоторых случаях у человека может создаваться впечатление, что созерцаемый момент длится долго, тогда как мускульнопсихическая реакция на него уже прошла. Запаздывание не снижает качества восприятия, но откуда же возникает психологическое время?

Поддерживая идею единства мира, Вундт полагает, что пространственные и временные реакции возникли вместе с формированием органов, физических и психических структур организма. Оставаясь в некоторой степени сторонником кантовского априоризма, Вундт отмечает, что пространство относится к внешним «первичным» свойствам таких чувственных областей, как осязание и зрение. Время же относится к внутренним свойствам осязательных и слуховых ощущений. Они дей- 
ствуют, если можно так сказать, ансамблевым способом. «Разница заключается однако же в том, - пишет Вундт, - что тогда как самостоятельная группировка впечатлений в пространстве возможна исключительно в области осязания и зрения, для группировки впечатлений во времени внутренняя осязательность и слуховые ощущения представляют только более благоприятные условия, но возможна она и для всех прочих ощущений» (Вундт, 1907: 96). Таким образом, как и в концепции Канта, время в своих функциональных возможностях превалирует над ограниченной формой пространства.

Однако если Кант не давал развернутого обоснования происхождения этой априорной формы чувственности (об этом еще будет сказано применительно к взглядам Н.Я. Грота), Вундт создает, не погружаясь в спекулятивные глубины, четкое объяснение формирования психологического времени из личного опыта субъекта. «Внутренняя осязательность» есть не что иное как ритмичные (преимущественно) и аритмичные двигательные реакции, связанные с раздражением. Совершая их, субъект усваивает идею последовательности и одновременности моментов, которую потом смутно или осознанно применяет в опыте. То же самое можно сказать и о слуховых ощущениях: приучаясь к тактовому характеру разнородных звучаний, субъект формирует в душе представления о последовательности явлений и их границах. Кроме того, Вундт допускает еще такое понятие как «длительность». В его интерпретации это - субъективное время, связанное с пространственными представлениями. Формально все моменты времени могут быть разложены на составляющие. Однако на практике каждый из них несет какое-то содержание и увязан с другими моментами. В психической жизни субъекта отдельные содержания могут превалировать над другими и находиться в «некотором отношении» к субъекту. Такого типа ситуации называются «течением времени». По мысли Вундта, они могут длиться дол- го, но «абсолютной длительности» не существует в силу того, что психическая жизнь связана с постоянной сменяемостью моментов и формированием новых содержаний и связей. Касательно чистых пространственных представлений, Вундт дает еще одну значимую характеристику, отчасти представленную выше: пространственные представления могут разыматься субъектом на части и перегруппировываться. Временные же представления пребывают в своей неизменности, в противном случае они утрачивают свою темпоральную целостность.

Краткая характеристика психологии времени у Вундта связана также с другим аспектом его понимания - метризацией скорости психических реакций. В Лейпцигской лаборатории с помощью хронометрических приборов он исследовал внимание и чувства, а также пытался установить временные стандарты для скорости мысли. Как известно, эта программа своего дальнейшего развития у психологов следующего поколения не получила.

\section{2. Экспериментальный и метафи- зический аспекты пространственных и временных характеристик}

Н.Я. Грот критично отнесся, прежде всего, к хронологической стандартизации В. Вундтом чувственных реакций человека, справедливо полагая, что если на первом этапе будут утверждать стандарты для «ощущений» и «чувствований», то на втором возьмутся за память и мышление, а на третьем - за единый духовный облик человека. «... Физиологи и психологи нашего времени, - пишет Грот, - стараются втиснуть душевную жизнь в границы и рамки времени. Созданная ими (в особенности Вундтом) наука - "психометрия" поставила себе прямою задачей перевести все явления душевной жизни в термины времени» (Грот, 1894б: 385). В чем же методологическая ошибка экспериментальных психологов?

К тому, что психологическое время возникает как реакция на «внутреннюю 
осязательность» и слуховые ощущения Грот претензий не предъявляет; его собственная психологическая концепция, о которой будет сказано ниже, поглощает эту идею. Грот не удовлетворен позитивистскими основаниями измерительных методов Вундта. Он пишет: «Мы уже не смешиваем клетку мозга и ее периферическое раздражение с последующим ощущением, но еще, очевидно, всё-таки смешиваем с ощущением центральный физиологический молекулярный процесс, или движения, которые в ней совершаются. Физиологические движения эти требуют времени, которое в долях секунды определяется при помощи особого часового механизма, называемого хроноскопом, и некоторых цифровых вычислений, и мы воображаем, что измерили этим время ощущщения. Не явная ли тут путаница понятий?» (Грот, 1894б: 386). По мысли Грота, с помощью измерительных приборов можно устанавливать скорости физиологических реакций индивида, но «ощущения» и «чувствования» испытывает личность, в деятельности которой формальные показатели не соотносимы с содержанием психических действий. Необходимо принципиально иное понимание психических реакций, которое Грот находит в идее энергетизма - взаимосвязи и переходе физической энергии в психическую при условии ее физического сохранения. Заметим, что, согласно исследованию Б.В. Межуева, на позднее развитие этой достаточно спорной концепции оказал влияние В.С. Соловьев (Межуев, 2018: 49). В рамках этой концепции время - «субъективное восприятие усилий, совершаемых при преодолении сопротивлений, представляемых физическими энергиями в телах...» (Грот, 1894б: 386). Какого типа эти усилия? По мысли Грота, психика субъекта замкнута в его организме и являет с ним единое системное личностное целое. Контактируя с физической средой, психика фиксирует сопротивления организма воздействию энергий разного объема. Например, при ходьбе мы испытываем легкое ритмичное напряжение мышц ног и спины, а при продолжительности этого действия состояние усталости. Те ощущения, которые возникают в результате внешнего энергетического воздействия, Грот называет «специальными», а те, которые возникают внутри организма - «общими». Кроме того, Грот, как и Вундт, отмечает разные источники формирования пространственных и временных форм: «Пространство есть преимущественно форма восприятий зрительных и осязательных, время форма восприятий слуховых и обонятельных» (Грот, 1894б: 408). Но, как мы знаем, процесс восприятия многогранен и затрагивает как периферические, так и центральные элементы психической системы. Грот выстраивает следующие иерархические модели совместного действия восприятий: а) элементарный уровень: удержание зрительных и осязательных ощущений приводит к чувству «протяжения» (пространство); удержание слуховых и обонятельных ощущений - к чувству «продолжительности» (время); переход от одних пространственных ощущений к другим - к восприятию «смежности»; переход от одних временных ощущений к другим к восприятию «последовательности»; б) высший уровень: взаимосвязь «протяжения» и «смежности» приводит к «совместности»; взаимосвязь «продолжительности» и «последовательности» к «преемству»; сочетание «совместности» и «преемства» приводит к «движению» - категории, выражающей взаимосвязь пространственных и временных характеристик ощущений (Грот, 1894б: 410). Таким образом, русский психолог демонстрирует сложную сеть реакций, посредством которых мы идентифицируем ощущения и, впоследствии, руководствуемся их содержаниями в повседневном чувственном опыте.

\section{3. Время как форма чувственного опыта и время как понятие}

Критикуя несоответствие понятий о пространстве и времени и их характеристик в «Критике чистого разума» И. Канта, Грот размышляет: «Само представление 
времени временно, или нет? Ведь поставил же он себе вопрос: "пространственно ли представление о пространстве”, и ответил: нет. Еще маленький шаг, еще один маленький вопрос, которого Кант себе не задал, - и всю "Критику чистого разума" пришлось бы переделать и свет не увидел бы "Трансцендентальной диалектики" Канта, которая есть строго-логическое развитие неверных посылок Канта о природе времени и об его значении в познавательной деятельности человека» (Грот, 1894a: 265). Грот же себе этот вопрос поставил и пришел к мысли, что если мы знаем предикаты времени: последовательность, одновременность и пр., то мы должны знать и что такое понятие «время». Следовательно, это не программа, которая вложена создателем в нашу душу, но понятие, сформированное мышлением относительно функционирования данных внутреннего и внешнего опыта. И, как и всякое понятие, оно относится к миру идей, не имеющих физических характеристик. «Сознать, а особенно понять эту истину, - пишет Грот, - нелегко, так как наша душевная жизнь насквозь пропитана чувственностью, чувственными восприятиями материальных предметов и явлений, и нужна довольно высокая степень самосознания и развития, чтобы быть в состоянии отличать в своем самосознании два тесно слитых факта - ощущение предмета и сознание или психическое восприятие этого ощущения» (Грот, 1894б: 384). Стало быть, вышеуказанные реакции как формы удержания или смены явлений контролируются самосознанием, которое само по себе имеет внепространственный и вневременный характер. Внешние данные интерпретируются самосознанием как символь чувственного опыта. При этом отношение ко времени может носить как «субъективный», так и «объективный» характер. Как и в случае с Вундтом, субъективное время проявляет себя в опыте личного переживания последовательности ощущений. Оно всегда априорно. «Объективное» отношение возникает в случаях, когда мы ищем соответствия нашим ощущениям и вырабатываем приемы его относительного отображения. Грот это представляет в рамках своей энергетической концепции так: «Но если так, то восприятие времени и пространства суть не только непосредственно формы восприятия психических усилий, но одновременно и косвенно формы восприятия оказываемых этими усилиями сопротивлений со стороны энергий, называемых “физическими”. Вот этито косвенно воспринимаемые нами суммы сопротивлений и суть объективное пространство и объективное время. А так как эти сопротивления в своих элементах и отношениях определены и подчинены известным законам, которые мы называем физическими или объективнылми, - подобно тому, как определены и устойчивые отношения, и законы соответствующих им психических усилий, то является возможность измерять первые при помощи последних и обратно» (Грот, 1894б: 411).

Может показаться, что Грот, так же как и Вундт, развивает идею применения физических методов к исследованию всех сфер проявления человеческой психики, о чем говорилось в начале статьи, но это совсем не так. Грот в работах о времени развивает один принципиальный момент, который остается актуальным и в современной когнитивной психологии: как соотносятся наши мысли, чувства, эмоции, память с физиологическими процессами нашего мозга? Русский философ и психолог заявляет, что психология пока этого не знает, что остается верить, что существует связь между душой и телом, подобно предустановленной гармонии, обозначенной еще Лейбницем. И, как мы знаем теперь, в этом заявлении Грот не совершает философского «отката» к принципам психологического механицизма. Он понимает, что чувственный и мыслительный уровни психики устроены принципиально иначе, чем физический мир, и приблизиться к их пониманию можно лишь опосредованно через правильное рассуждение, то есть через метафизику. 
Таким образом, концепции времени Грота и Вундта частично соотнесены: оба философа полагают, что психологическое время формируется на основе слуховых и обонятельных (Грот) или осязательных (Вундт) ощущений. Оба философа утверждают, что в конкретном опыте психологическое время проявляется во взаимодействии с психологическим пространством, порожденным другими ощущениями. И Вундт, и Грот помимо «субъективного» выделяют и «объективное» время, у которого во внешнем мире есть свои физические корреляты. Однако если Вундт полагает, что с помощью психометрических приборов можно установить временные стандарты психических и мыслительных реакций, то Грот настаивает на том, что психический мир связан с физиологией опосредованно, и к содержательной стороне ощущений и мышления психометрические методики не применимы. Исходя из идеи энергетического перехода из физического в психическое, Грот считает, что мысли и чувства возможно исследовать исключительно через метафизику.

\section{Литература}

Вундт, В. Очерк психологии. СПб.: Издание Ф. Павленкова, 1907. 229 с.

Грот, Н.Я. Джордано Бруно и пантеизм. Философский очерк. Одесса: Типография «Одесского вестника», $1885.90 \mathrm{c}$.

Грот, Н.Я. О времени // Вопросы философии и психологии. 1894а, № 23 (3). С. 248-330.

Грот, Н.Я. О времени (продолжение) // Вопросы философии и психологии. 1894б, № 24 (4). С. 381-490.

Межуев, Б.В. Владимир Соловьев и Николай Грот: парадоксы взаимовлияния // Соловьевские исследования. 2018. № 3 (59). С. 43-58.

Соловьев, В.С. Статьи // Н. Я. Грот в очерках, воспоминаниях и письмах товарищей и учеников, друзей и почитателей. СПБ. Типография Министерства Путей Сообщения, 1911. C. $148-156$.

Соловьев, В.С. Рецензия на книгу Вундта «Лекции о душе человека и животных» URL: http://www.odinblago.ru/soloviev_7/10 (дата обращения 7.12.2019).

Шульц, Д.П., Шульц, С.Э. История современной психологии. СПб.: «Евразия», 2002 г. 532 с.

\section{References}

Groth, N.J. (1894a), "About the time", Voprosi filosofii i psikhologii, 23 (3), 248-330 (in Russ).

Groth, N.J. (1894b), "About the time", Voprosi filosofii i psikhologii, 24 (4), 381-490 (in Russ).

Groth, N.J. (1885), Dzhordano Bruno $i$ panteism [Giordano Bruno and pantheism], "Odesskiy vestnik", Odessa, Russia (in Russ).

Mezhuev, B.V. (2018), "Vladimir Solovyov and Nikolai Groth: paradoxes of mutual influence", Solovyov studies, 3 (59), 43-58 (in Russ).

Schultz, D. P. and Schultz S.E. (2002), Istoria sovremennoy psikhologii [A History of Modern Psychology], transl. by Govorunov A.V., Kuzin V.I., Tsaruk L.L., Evrazia， St. Petersburg, Russia (in Russ).

Solovyov, V.S. (1911), "Essay", N.J. Groth $v$ ocherkah, vospominaniyah i pis'mah tovarishhej $i$ uchenikov, druzej i pochitatelej, 148-156 (in Russ).

Solovyov, V. (1895) Review of Wundt's book "Lectures on the soul of man and animals" [Online], available

at: http://www.odinblago.ru/soloviev_7/10 (accessed 07 December 2019) (in Russ).

Wundt, W. (1907), Ocherk psikhologii [Essay in Psychology], transl. by G.A. Paperna, ed. F. Pavlenkova, St. Petersburg, Russia (in Russ).

Информация о конфликте интересов: автор не имеет конфликта интересов для деклараций.

Conflict of Interests: the author has no conflict of interests to declare.

\section{OБ АВTOPE:}

Савинцев Вячеслав Игоревич, кандидат философских наук, доцент кафедры философии, исторический факультет, Балтийский федеральный университет имени Иммануила Канта, ул. А. Невского, д. 14, г. Калининград 236016, Россия; vyacheslav-savincev@yandex.ru

\section{ABOUT THE AUTHOR:}

Vyacheslav I. Savintsev, Associate Professor, Department of Philosophy, Faculty of History, Immanuel Kant Baltic Federal University, 14 A. Nevsky St., Kaliningrad 236016, Russia; vyacheslav-savincev@yandex.ru 